\title{
miR-320a-3P alleviates the epithelial-mesenchymal transition of A549 cells by activation of STAT3/SMAD3 signaling in a pulmonary fibrosis model
}

\author{
XIN WANG $^{1}$, JING WANG ${ }^{2}$, GUICHUAN HUANG ${ }^{1}$, YISHI LI $^{1}$ and SHULIANG GUO ${ }^{1}$ \\ ${ }^{1}$ Department of Respiratory Medicine, The First Affiliated Hospital of Chongqing Medical University, Chongqing 400016; \\ ${ }^{2}$ Department of Pharmacy, People's Hospital of Deyang City, Deyang, Sichuan 618000, P.R. China
}

Received September 8, 2020; Accepted February 18, 2021

DOI: $10.3892 / \mathrm{mmr} .2021 .11996$

\begin{abstract}
Pulmonary fibrosis (PF) is a common, chronic and incurable lung disease, in which the lungs become scarred over time. MicroRNAs (miRNAs/miRs) serve key roles in various biological processes, including cell proliferation, differentiation, apoptosis and the regulation of epithelial-mesenchymal transition (EMT) process. The aim of the present study was to investigate the underlying mechanism of miR-320a-3p as a potential therapeutic target for PF. Clinical samples and microarray datasets collected from various databases were used to evaluate the expression of miR-320a-3p in PF. A549 cells were used to construct an EMT model of PF. A dual-luciferase reporter assay system was used to identify target genes of miR-320a-3p. Western blot analysis and immunofluorescence staining were used to determine the roles of miR-320a-3p and its target genes in the EMT process in PF. The present study found that, compared with lung tissue of healthy control subjects, the expression of miR-320a-3p in lung tissue of PF patients was significantly reduced. The expression levels of miR-320a-3p decreased in TGF- $\beta 1$-stimulated A549 cells in a time- and concentration-dependent manner. The overexpression of miR-320a-3p suppressed EMT markers induced by TGF- $\beta 1$ in A549 cells and STAT3 was identified as a potential target gene of miR-320a-3p. Furthermore, the expression changes of miR-320a-3p and STAT3 were found to significantly affect the expression of phosphorylated SMAD3 in TGF- $\beta 1$-stimulated A549 cells. Briefly, overexpression of miR-320a-3p could inhibit the EMT process in PF by downregulating STAT3 expression. The mechanism mediating these
\end{abstract}

Correspondence to: Professor Shuliang Guo, Department of Respiratory Medicine, The First Affiliated Hospital of Chongqing Medical University, 1 Youyi Road, Chongqing 400016, P.R. China E-mail: guos1999@sina.com

Key words: pulmonary fibrosis, epithelial-mesenchymal transition, A549, miR-320a-3p, STAT3, SMAD3 effects may partly involve crosstalk between the SMAD3 and STAT3.

\section{Introduction}

Pulmonary fibrosis (PF) is a common, chronic and incurable disease, which is characterized by lung tissue scarring and the destruction of lung tissue structure (1). Despite the development of various detection methods and clinical treatments, PF remains a major public health problem that inevitably leads to a decline in lung function, progressive respiratory failure and high mortality $(2,3)$. Increasing evidence suggests that a possible mechanism for the pathogenesis of PF involves epithelial-mesenchymal transition (EMT) (4,5), a transdifferentiation process in which epithelial cells are ultimately converted into motility mesenchymal cells with increased collagen deposition and other extracellular matrix components characteristic of alveolar epithelial cells (AECs). The main mediator of EMT is TGF $\beta-1$, which can upregulate the expression of pro-fibrotic genes, such as vimentin, $\alpha$-smooth muscle actin ( $\alpha$-SMA; ACTA2) and collagen 1 and downregulate the expression of epithelial cell-related genes, such as $C D H 1$. TGF $\beta-1$-induced EMT serves a crucial role in fibrosis in various organs (6) and AECs are among its important target cells, which can convert into a mesenchymal phenotype through TGF $\beta$-1-induced EMT, thereby promoting PF.

MicroRNAs (miRNAs/miRs) are small, noncoding RNAs that inhibit gene expression by binding to the 3 -untranslated regions (3'-UTR) of the mRNA of their target genes. There is increasing evidence that miRNAs serve critical roles in various biological processes, including cell proliferation, differentiation, apoptosis and regulation of the EMT process (7-9). The miRNA miR-320a-3p is known to be involved in the regulation of EMT and studies have shown that it serves important roles in the regulation of the EMT process in various tumors $(10,11)$. However, whether miR-320a-3p can regulate the EMT process in PF has yet to be investigated.

The present study used the Gene Expression Omnibus (GEO) and ArrayExpress databases as relevant data sources to analyze the differential expression of miR-320a-3p in PF and normal lung tissues and then verified the relative expression levels of miR-320a-3p in clinical samples. In addition, the 
regulatory mechanism of miR-320a-3p mediating the attenuation of PF was explored through experimental cellular studies.

\section{Materials and methods}

Data acquired from the GEO and ArrayExpress databases. The relevant expression level data of miR-320a-3p in PF tissues and normal tissue specimens were obtained from the GEO (http://www.ncbi.nlm.nih.gov/gds/) and the ArrayExpress (https://www.ebi.ac.uk/arrayexpress/) databases. The following key words were used as search terms: 'lung fibrosis', 'idiopathic pulmonary fibrosis (IPF)', 'microRNA (miRNA)', 'miR320a'. The following criteria were strictly followed: i) Study type: Expression profiling by microarray; ii) datasets were derived from Homo sapiens; iii) datasets included interstitial lung fibrosis tissues and normal tissues; iv) the datasets included $>5$ samples in each group; and v) the expression data of miR320a from the patients and control subjects were clearly defined and provided. Potentially relevant datasets were further screened by reviewing titles, summaries and overall design. Relevant full articles and samples information were evaluated in order to identify studies that met the eligibility criteria. The data of eligible datasets and series were current to June 2020. Basic information about enrolled datasets are listed in Table SI.

Collection of clinical samples. The PF tissue samples ( $\mathrm{n}=12$; sex ratio between male and female was 1:2; age range, 39-78 years) were collected by bronchoscopic lung cryobiopsy performed in the Department of Respiratory Medicine of the First Affiliated Hospital of Chongqing Medical University. Normal control samples ( $\mathrm{n}=17$; sex ratio between male and female was 1:1.43; age range, 47-77 years) were obtained from normal tissues adjacent to cancer tissues collected in the Department of Cardiothoracic Surgery of the First Affiliated Hospital of Chongqing Medical University. The recruitment dates for the patients were between June and December 2020. The two sets of samples were collected and frozen in liquid nitrogen for subsequent RNA extraction and reverse transcription-quantitative (RT-q) PCR. The collection and analysis procedures of all samples were approved by the Ethics Research Institute of the First Affiliated Hospital of Chongqing Medical University (approval no. 2020-147-2) and written informed consent was obtained from all the participants. Information on patients is listed in Table SII.

Cell culture and transfection. The adenocarcinomic human alveolar basal epithelial cell line, A549, was provided by the Stem Cell Bank, Chinese Academy of Science (Shanghai, China). Cells were cultured in RPMI-1640 medium (Gibco; Thermo Fisher Scientific, Inc.), supplemented with $10 \%$ fetal bovine serum Premium (PAN-Biotech $\mathrm{GmbH}$ ) and $100 \mathrm{IU} / \mathrm{ml}$ penicillin and $100 \mu \mathrm{g} / \mathrm{ml}$ streptomycin (Gibco; Thermo Fisher Scientific, Inc.) in a humidified incubator at $37^{\circ} \mathrm{C}$ with a $5 \% \mathrm{CO}_{2}$ atmosphere. A549 cells were transfected with miR-320a-3p mimic, signal transducer and STAT3 short interfering (si)RNA or corresponding negative control (NC; Shanghai GenePharma Co., Ltd.) using Lipofectamine ${ }^{\circledR} 3000$ (Invitrogen; Thermo Fisher Scientific, Inc.) according to the manufacturer's instructions. Following transfection for $24 \mathrm{~h}$, the cells were treated with or without TGF- $\beta 1$ (PeproTech, Inc.) for $48 \mathrm{~h}$ and then harvested for subsequent experiments. The si-NC and mimic-NC were non-targeting sequences. The HBLV-h-STAT3-3xflag-mcherry-PURO (HBLV-h-STAT3) and HBLV-mcherry-PURO (HBLV-NC) were constructed by Hanbio Biotechnology Co., Ltd. A549 cells were transfected with HBLV-h-STAT3 or HBLV-NC and puromycin was used to select cells with functional transfection status (DIYIBio Inc.). The transfection sequences are listed in Table I.

$R T-q P C R$. A549 cells ( $1 \times 10^{5}$ per well) were seeded in the 6-well plate for total RNA extraction. Total RNA was isolated from clinical samples and cultured cells using RNAiso Plus (Takara Bio, Inc.) according to the manufacturer's instructions. RNA was reverse transcribed using the PrimeScript RT Reagent kit with genomic DNA (gDNA) Eraser (Takara Bio, Inc.). The gDNA elimination reaction was performed for $2 \mathrm{~min}$ at $42^{\circ} \mathrm{C}$. Reverse transcription was conducted for $15 \mathrm{~min}$ at $37^{\circ} \mathrm{C}$ and $5 \mathrm{sec}$ at $85^{\circ} \mathrm{C}$. The qPCR analysis was performed using the CFX96 real-time PCR system (Bio-Rad Laboratories, Inc.) and the TB Green Premix EX Taq II PCR kit (Takara Bio, Inc.). Amplification consisted of an initial $30 \mathrm{sec}$ incubation at $95^{\circ} \mathrm{C}$, followed by 40 cycles of $5 \mathrm{sec}$ at $95^{\circ} \mathrm{C}$ and $30 \mathrm{sec}$ at $60^{\circ} \mathrm{C}$. Data were expressed as the relative differences between the control and treated cells after normalization to GAPDH expression. To determine the relative expression levels of miRNAs, the U6 small nuclear RNA was used for normalization. The relative expression levels of the mRNA and miRNA was calculated using the $2^{-\Delta \Delta C q}$ method (12). Primers for miR-320a-3p and U6 were purchased from GenePharma Co. Ltd., while those for $G A P D H, A C T A 2$, vimentin, $C D H 1$ were purchased from Takara Bio, Inc. The sequence of the primers used are listed in Table II. All experiments were repeated three times.

Western blot analysis. The total protein content of the cells was extracted by using radio immunoprecipitation assay (RIPA) lysis buffer (Beyotime Institute of Biotechnology) which contained $1 \%$ phosphatase inhibitor (Wuhan Boster Biological Technology, Ltd.) and 1\% phenylmethanesulfonyl fluoride (Beyotime Institute of Biotechnology). Total protein concentration was measured using a bicinchoninic acid protein assay kit (Beyotime Institute of Biotechnology). For western blotting, $20 \mu \mathrm{g}$ of protein was loaded into each lane of the $10 \%$ sodium dodecyl sulfate-polyacrylamide gel electrophoresis gels, followed by electrophoresis and protein transfer to polyvinylidene fluoride membranes (EMD Millipore). Following transfer, the membranes were blocked with QuickBlock ${ }^{\mathrm{TM}}$ blocking buffer for western blotting (Beyotime Institute of Biotechnology) for $15 \mathrm{~min}$ at room temperature. The primary antibodies rabbit anti-E-cadherin (1:10,000; cat. no. ab40772), rabbit anti-vimentin (1:3,000; cat. no. ab92547), rabbit anti- $\alpha$-SMA (1:3,000; cat. no. ab32575) and rabbit anti-GAPDH (1:10,000; cat. no. ab181602) were purchased from Abcam. The rabbit anti-phosphorylated (p-)STAT3 (Tyr705, 1:2,000; cat. no. 9145), mouse anti-STAT3 (1:1,000; cat. no. 9139), rabbit anti-p-SMAD3 (Ser423/425, 1:1,000; cat. no. 9520) and rabbit anti-SMAD3 (1:1,000; cat. no. 9523) were purchased from Cell Signaling Technology, Inc. Immunoblots were probed with the corresponding primary antibody at $4^{\circ} \mathrm{C}$ overnight and subsequently with the appropriate secondary antibody 
Table I. Transfection sequences used in the present study.

Name Sequence $\left(5^{\prime}-3^{\prime}\right)$

hsa-miR-320a-3pmimics-F

hsa-miR-320a-3pmimics-R

Negative control-F

Negative control-R

si-STAT3-F

si-STAT3-R

si-Negative control-F

si-Negative control-R
5'-AAAAGCUGGGUUGAGAGGGCGA-3'

5'-GCCCUCUCAACCCAGCUUUUUU-3'

5'-UUGUACUACACAAAAGUACUG-3'

5'-GUACUUUUGUGUAGUACAAUU-3'

5'-GCAACAGAUUGCCUGCAUUTT-3'

5'-AAUGCAGGCAAUCUGUUGCTT-3'

5'-UUCUCCGAACGUGUCACGUTT-3'

5'-ACGUGACACGUUCGGAGAATT-3'

hsa, Homo sapiens; miR, microRNA; si, short interfering.

Table II. Primers used in the present study.

Name

Sequence (5'-3')

GAPDH-F
GAPDH-R
ACTA2-F
ACTA2-R
CDH1-F
CDH1-R
vimentin-F
vimentin-R
hsa-miR-320a-3p-F
hsa-miR-320a-3p-R
U6-F
U6-R

5'-CTTTGGTATCGTGGAAGGACTC-3'

5'-GTAGAGGCAGGGATGATGTTCT-3'

5'-CCCTTGAGAAGAGTTACGAGTTG-3'

5'-CATGATGCTGTTGTAGGTGGTT-3'

5'-CGATTCAAAGTGGGCACAGATG-3'

5'-GTAGGTGGAGTCCCAGGCGTAG-3'

5'-TCTGGATTCACTCCCTCTGGTT-3'

5'-ATCGTGATGCTGAGAAGTTTCGT-3'

5'-ATGAGAAAAAGCTGGGTTGAGA-3'

5'-TATGGTTTTGACGACTGTGTGAT-3'

5'-CAGCACATATACTAAAATTGGAACG-3'

5'-ACGAATTTGCGTGTCATCC-3'

F, forward; R, reverse; hsa, Homo sapiens; miR, microRNA.

(1:8,000; cat. no. ZB-2301; OriGene Technologies, Inc.) for $1 \mathrm{~h}$ at room temperature. The protein bands on the membranes were visualized with enhanced chemiluminescence reagent (Vazyme Biotech Co., Ltd.) and images were captured using an automatic Fusion FX Edge chemiluminescence image analysis system (Vilber Lourmat Sa). Densitometric analysis of the blot images was performed using the Fusion Capt software v.18.06 (Vilber Lourmat Sa). GAPDH was used as an internal normalizer.

Immunofluorescence staining and fluorescence microscopy. Cells $\left(5 \times 10^{4}\right.$ per well) were seeded and grown in 6-well plates with cell culture silicon slides. Following treatment, the cells were fixed in $4 \%$ paraformaldehyde for $20 \mathrm{~min}$ at room temperature, then permeabilized with $0.2 \%$ Triton X-100 in PBS for $20 \mathrm{~min}$ at room temperature (rinsed three times with PBS between each step). Non-specific binding sites were blocked with 3\% BSA (Wuhan Servicebio Technology Co., Ltd.) for $30 \mathrm{~min}$ at room temperature. The cells were then incubated overnight at $4{ }^{\circ} \mathrm{C}$ with the corresponding primary antibody at a 1:200 dilution. Afterwards, the cells were incubated with the appropriate fluorescein-conjugated secondary antibody for $1 \mathrm{~h}$ in the dark at $37^{\circ} \mathrm{C}$. Primary antibodies and secondary antibodies were purchased from Wuhan Servicebio Technology Co., Ltd. The fluorescent stain 4',6-diamidino-2-phenylindole (DAPI) was used to stain cell nuclei for $10 \mathrm{~min}$ in the dark at room temperature before image acquisition. The images were acquired using a fluorescence microscope (Nikon Corporation) with $\mathrm{x} 40$ magnification. The red fluorescence indicated positive antibody expression and the blue fluorescence indicated nuclear DAPI staining. Mean gray value analysis was performed using the ImageJ software v1.53e (National Institutes of Health).

Firefly and Renilla dual-luciferase assay. The target genes of miR-320a-3p were identified using the miRanda (http://www. microrna.org/microrna/home.do), miRWalk (http://mirwalk. umm.uni-heidelberg.de/) and PITA (http://genie.weizmann.ac.il/pubs/mir07/mir07_data.html) algorithms. The dual-luciferase reporter system was used to validate the target relationship between miR-320a-3p and STAT3. 
Human STAT3 3'-UTR containing a 3'-UTR with mutated (mu) sequences complementary to the seed sequence of miR-320a-3p was inserted into the pSI-Check2 vector (Promega Corporation). The wild type (wt) STAT3 3'-UTR sequence was also inserted into the pSI-Check2 vector. Luciferase reporter plasmid was constructed and provided by Hanbio Biotechnology Co., Ltd. The A549 cells were grown in 96-well plates and then co-transfected with miR-320a-3p mimic or NC and pSI-Check2-STAT3-mu-3'-UTR or wt pSI-Check2-STAT3-3'-UTR using transfection reagent LipoFiter (Hanbio Biotechnology Co., Ltd.). Then, $6 \mathrm{~h}$ after transfection, the medium was replaced with fresh medium and after $48 \mathrm{~h}$, the dual-luciferase reporter system (Promega Corporation) was used to measure luciferase activity. The normalized luciferase activity was expressed as the ratio of Renilla luciferase activity to firefly luciferase activity (Rluc/fluc).

Statistical analysis. Data were expressed as the mean \pm standard deviation and SPSS v25 software (IBM Corp.) was used for data analysis. Independent-samples t-test was used for the analysis of data between two groups. Differences among three or more groups were compared using one-way analysis of variance followed by Tukey's post hoc test. GraphPad Prism v8.0 (GraphPad Software, Inc.) was used to draw the box plot, symbols and lines plot and column bar graph. $\mathrm{P}<0.05$ was considered to indicate a statistically significant difference.

\section{Results}

Expression of miR-320a-3p in PF. A total of 3 datasets were selected for the present study, according to the inclusion criteria (GSE21394/E-GEOD-21394, GSE32538/ E-GEOD-32538 and GSE27430/E-GEOD-27430). With the combination of datasets from the GEO and ArrayExpress database, a total of 174 PF samples were included. Sample sizes ranged from 13-142 subjects and the pathological types include the usual interstitial pneumonia/idiopathic pulmonary fibrosis (UIP/IPF), cryptogenic organic pneumonia (COP), desquamative interstitial pneumonia (DIP), nonspecific interstitial pneumonia (NSIP), connective tissue disease-associated interstitial lung disease (CTD-ILD) and respiratory bronchiolitis-associated interstitial lung disease (RB-ILD). It was found that two results in the analysis of three datasets showed that the relative expression levels of miR-320a-3p were significantly lower in PF tissue samples compared with normal tissue samples $(\mathrm{P}<0.05, \mathrm{P}<0.0001$; Fig. $1 \mathrm{~A}$ and $\mathrm{B})$. The remaining analyses showed that the relative expression levels of miR-320a-3p decreased in the PF group, but the difference was not statistically significant (Fig. 1C). Based on the results of the analysis of the datasets, clinical tissue samples of PF patients $(\mathrm{n}=12)$ and normal control subjects $(n=17)$ were collected. The pathological types of samples of PF included UIP/IPF, NSIP, COP and CTD-ILD. The tissue of the control group was confirmed to be normal tissue by pathology. The data showed that the relative expression levels of miR-320a-3p were markedly decreased in PF tissue samples compared with normal tissue samples (Fig. 1D).
miR-320a-3p is decreased in TGF- $\beta 1$-stimulated A549 cells and elevates expression levels of miR-320a-3p inhibited EMT. The A549 cell lines is widely used as a model system to study the mechanisms of the EMT process in PF. In the present study, qPCR analysis was first used to determine the relative expression levels of miR-320a-3p in A549 cells stimulated for $48 \mathrm{~h}$ with TGF- $\beta 1$ at different concentrations $(0,1,3,5$ and $10 \mathrm{ng} / \mathrm{ml})$. It was found that TGF- $\beta 1$ significantly reduced the miR-320a-3p expression levels compared with the control group and the optimal inhibitory effect was obtained at a concentration of $10 \mathrm{ng} / \mathrm{ml}$ (Fig. 2A). Subsequently, the levels of miR-320a-3p in A549 cells stimulated with $10 \mathrm{ng} / \mathrm{ml}$ of TGF- $\beta 1$ was determined at various time points $(0,24$ and $48 \mathrm{~h})$ and it was found that the optimal inhibition was achieved at $48 \mathrm{~h}$ (Fig. 2B). After transfecting A549 cells with miR-320a-3p mimic and $\mathrm{NC}$, followed by treatment with TGF- $\beta 1(10 \mathrm{ng} / \mathrm{ml})$ for $48 \mathrm{~h}, \mathrm{qPCR}$ analysis was used to determine the expression levels of mRNA of $C D H 1$, vimentin and ACTA2. The results showed that compared with the TGF- $\beta 1$ treatment group, miR-320a-3p mimic treatment increased the expression of mRNA of $C D H 1$ and significantly decreased the expression of mRNA of vimentin and ACTA2. Western blot analysis and immunofluorescence staining was also used to examine the expression of the epithelial phenotype marker E-cadherin and the mesenchymal phenotype markers vimentin and $\alpha$-SMA. The results showed that compared with the corresponding control group, TGF- $\beta 1$-induced EMT increased the expression of vimentin and $\alpha$-SMA and significantly reduced the expression of E-cadherin. miR-320a-3p mimic treatment attenuated the above effects, that is, it restored the expression of E-cadherin and reduced the expression of vimentin and $\alpha$-SMA (Fig. 2C-E). These findings indicated that TGF- $\beta 1$ can induce EMT changes in A549 cells and miR-320a-3p mimic can inhibit those EMT changes. The transfection efficiency of miR-320a-3p mimic is shown in Fig. 2F.

STAT3 is essential for the modulation of TGF- $\beta 1$-induced EMT in A549 cells by miR-320a-3p. To further investigate the mechanism, several bioinformatics analyses were conducted and the results revealed that STAT3 is a potential target of miR-320a-3p. A dual-luciferase reporter assay was then conducted and revealed that the miR-320a-3p mimic significantly inhibited the luciferase activity in the wt pSI-Check2-STAT3-3'-UTR group compared with the mimic-NC group $(\mathrm{P}<0.01$; Fig. $3 \mathrm{~A}$ and $\mathrm{B})$. However, the miR-320a-3p mimic did not influence the luciferase activity of pSI-Check2-STAT3-mut-3'-UTR. Western blot analysis also showed that miR-320a-3P inhibited the expression of both STAT3 and p-STAT3 in TGF- $\beta 1$-stimulated A549 cells, but not the ratio of p-STAT3 and STAT3 (Fig. 3C), indicating that miR-320a-3p directly regulated STAT3 expression. STAT3 is a member of a family of cytokine-responsive transcription factors and has been identified as being hyperphosphorylated during EMT (13). Accordingly, it was investigated whether the expression of STAT3 is involved in TGF- $\beta 1$-induced EMT in A549 cells. Therefore, A549 cells were transfected with STAT3 siRNA and NC siRNA and then treated them with TGF- $\beta 1(10 \mathrm{ng} / \mathrm{ml})$ for $48 \mathrm{~h}$. The results showed that, 

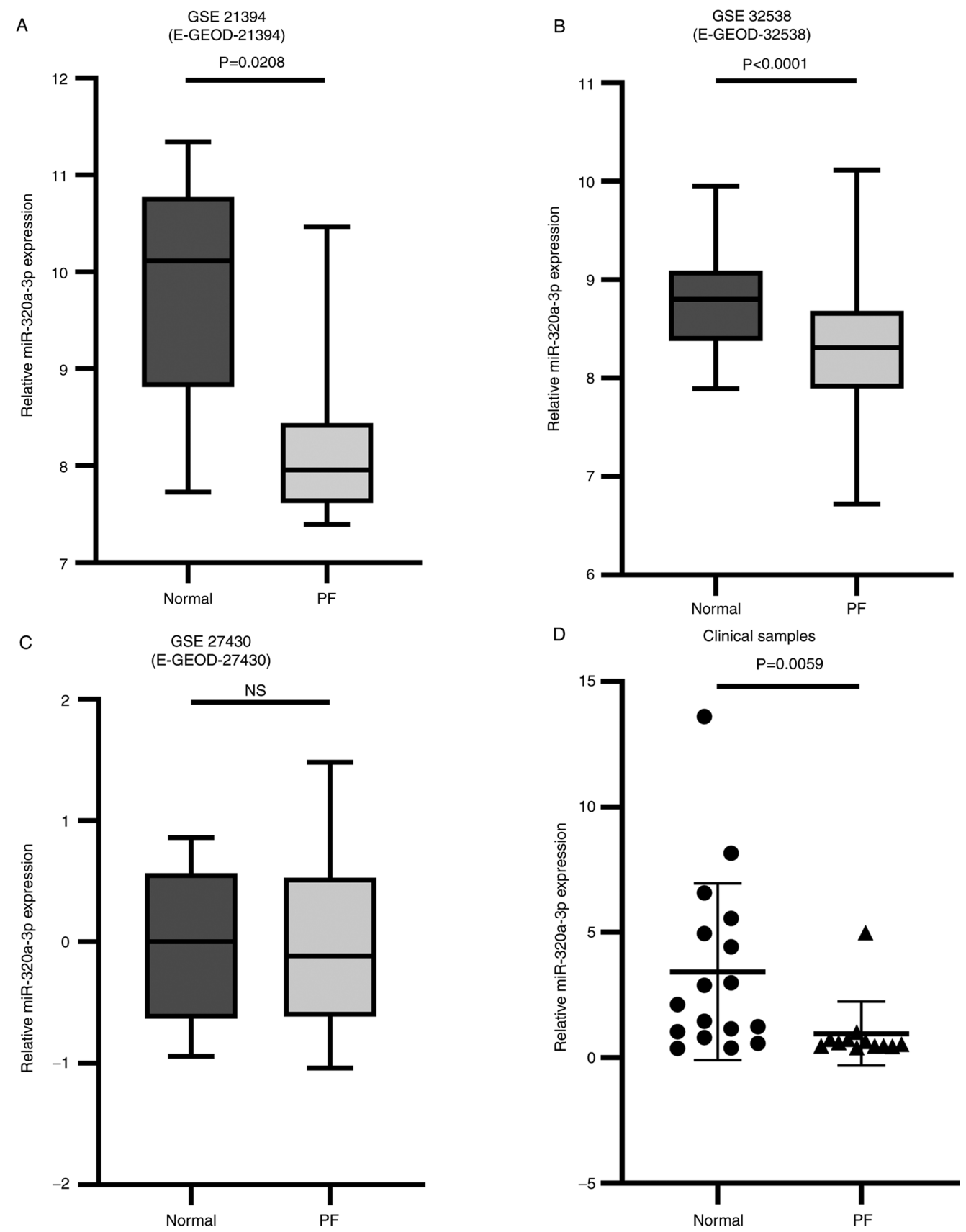

Figure 1. Expression levels of miR-320a-3p in PF tissue samples and normal tissue samples. (A-C) The relative expression levels of miR-320a-3p were measured in of three datasets, which were mined from the GEO and ArrayExpress databases. (D) The relative expression levels of miR-320a-3p in clinical samples were determined by reverse transcription-quantitative PCR. miR, microRNA; PF, pulmonary fibrosis; GEO, gene expression Omnibus; NS, no significant difference.

compared with the control group, STAT3 siRNA reduced the expression of vimentin and $\alpha$-SMA, while the expression of E-cadherin was significantly increased (Fig. 3D). To further confirm that miR-320a-3p mimic inhibited TGF- $\beta 1$-induced EMT in A549 cells through a STAT3-dependent mechanism, miR-320a-3p mimic was co-transfected with HBLV-h-STAT3 or HBLV-NC into A549 cells. Compared with mock-transfected cells, HBLV-h-STAT3 significantly increased the expression of STAT3. In addition, the upregulation of STAT3 inhibited the effect of the miR-320a-3p mimic on the expression of E-cadherin and significantly increased the expression of vimentin, $\alpha$-SMA and p-STAT3 (Fig. 3E). In summary, the above data indicated that miR-320a-3p mimic can attenuate
TGF- $\beta 1$-induced EMT in A549 cells by targeting STAT3 and p-STAT3. The transfection efficiency of si-STAT3 and HBLV-h-STAT3 are shown in Fig. 3F and G.

miR-320a-3p negatively regulates the phosphorylation of SMAD3. Following transfection of A549 cells with miR-320a-3p mimic, the expression of p-SMAD3 induced by TGF- $\beta 1$ was significantly reduced, while total SMAD3 was unaffected (Fig. 4A). Therefore, it was investigated whether the inhibitory effect of miR-320a-3p on the phosphorylation of SMAD3 was mediated by STAT3. To this end, the A549 cells were first transfected with STAT3 siRNA and it was confirmed that knocking down STAT3 led to reduced 

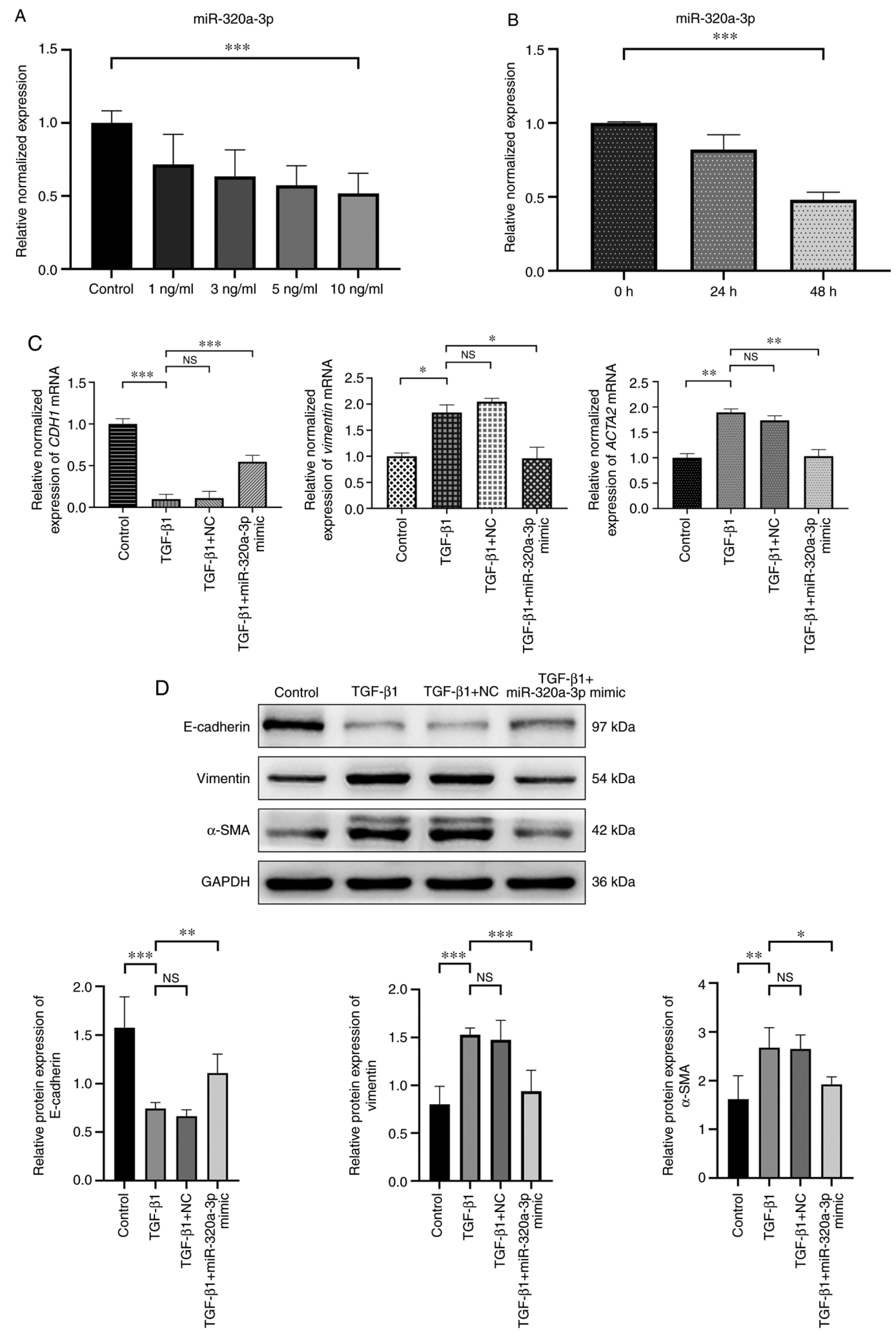

Figure 2. Continued

expression of p-SMAD3 induced by TGF- $\beta 1$ (Fig. 4B). Then, transfecting A549 cells with HBLV-h-STAT3 revealed that overexpression of STAT3 can significantly increase the expression of p-SMAD3 induced by TGF- $\beta 1$ (Fig. 4C). Taken together, these findings suggested that miR-320a-3p inhibited TGF- $\beta 1$-induced EMT in A549 cells partly by modulating the expression of STAT3 and p-SMAD3.

\section{Discussion}

EMT of epithelial cells serves a functional role in the development and progression of PF. Increasing evidence has shown that miRNAs can regulate PF (14-16). The present study first undertook to mine the expression data of miR-320a-3p in PF tissue samples by analyzing the datasets 

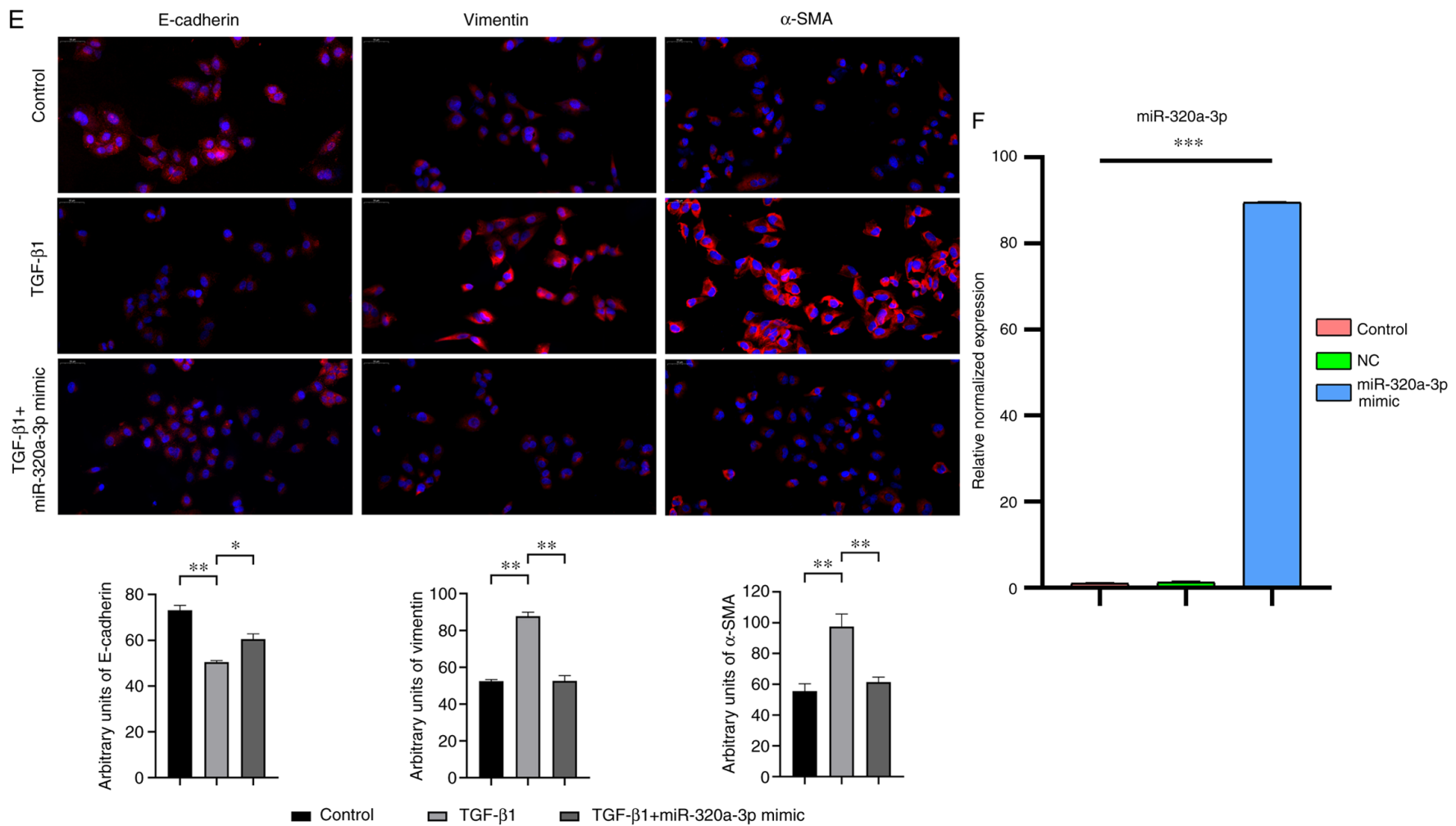

Figure 2. Expression levels of miR-320a-3p in A549 cells and the effects of miR-320a-3p on EMT in TGF- $\beta 1$-stimulated A549 cells. (A) A549 cells were treated with different concentrations $(0,1,3,5$ and $10 \mathrm{ng} / \mathrm{ml})$ of TGF- $\beta 1$ for $48 \mathrm{~h}$. (B) A549 cells were treated with $10 \mathrm{ng} / \mathrm{ml} \mathrm{TGF}-\beta 1 \mathrm{for} 0,24 \mathrm{and} 48 \mathrm{~h}$. The relative expression levels of miR-320a-3p in A549 cells measured by RT-qPCR. (C) A549 cells were treated with or without TGF- $\beta 1$ (10 ng/ml) for 48 h after transfection with miR-320a-3p mimic or NC. The relative expression levels of CDH1, vimentin and ACTA2 were determined by RT-qPCR. (D) A549 cells were treated with or without TGF- $\beta 1$ (10 ng/ml) for $48 \mathrm{~h}$ following transfection with miR-320a-3p mimic or NC. To confirm the occurrence of EMT, the expression of E-cadherin, vimentin and $\alpha$-SMA were determined by western blot analysis. (E) Immunofluorescence staining showed that the levels of vimentin and $\alpha$-SMA were reduced in miR-320a-3p mimic treated cells compared with those in cells treated with TGF- $\beta 1$, while levels of E-cadherin were increased. E-cadherin, vimentin and $\alpha$-SMA (red); DAPI-counterstained nuclei (blue). Magnification, $\mathrm{x} 40$, scale bar=50 $\mu \mathrm{m}$. (F) The transfection efficiency of miR-320a-3p mimic was determined by RT-qPCR. Error bars represent the standard deviation of three experiments. ${ }^{*} \mathrm{P}<0.05,{ }^{* *} \mathrm{P}<0.01,{ }^{* * * *} \mathrm{P}<0.001$. miR, microRNA; EMT, epithelial-mesenchymal transition; NC, negative controls; $\alpha$-SMA, $\alpha$-smooth muscle actin; NS, no significant difference; RT-qPCR, reverse transcription-quantitative PCR.

in the GEO and ArrayExpress databases. Although there was a considerable amount of high-throughput data in these databases, only three datasets that met the inclusion criteria were found. As it was implausible that the three datasets could produce an effective meta-analysis, only the statistical results of each data set analysis are listed. Of these, two results revealed that the relative expression levels of miR-320a-3p in PF tissue samples were significantly reduced compared with those in normal tissue samples. The results from the remaining analysis showed that the relative expression levels of miR-320a-3p were not statistically different between PF and normal tissue samples. Accordingly, the present study undertook to determine the relative expression levels of miR-320a-3p in clinical PF tissue samples. The pathological types of the clinical samples in the present study included UIP/IPF, NSIP, COP and CTD-ILD and the results confirmed that the relative expression levels of miR-320a-3p were markedly decreased in PF tissues sample compared with those in normal tissue samples, suggesting that miR-320a-3p might be have a regulatory role in EMT changes during PF.

A549 cells are adenocarcinomic human type II alveolar epithelial cells. After 3 days of in vitro culture, primary type II alveolar epithelial cells will be transformed into type I alveolar epithelial cells. For this reason, A549 cells have become a standard cell model to study the process of EMT in PF in vitro $(17,18)$. The role served by miR-320a-3p in the EMT process in PF was confirmed by qPCR analysis of the expression of miR-320a-3p in A549 cells treated with or without TGF- $\beta 1$, which revealed that treatment with TGF- $\beta 1$ decreased the relative expression levels of miR-320a-3p in a time- and concentration-dependent manner. Based on the aforementioned experimental results, $10 \mathrm{ng} / \mathrm{ml}$ for $48 \mathrm{~h}$ was chosen as the optimal TGF- $\beta 1$ treatment dose for subsequent experiments. Western blot analysis and immunofluorescence staining of miR-320a-3p mimic-transfected A549 cells stimulated with TGF- $\beta 1$ showed that overexpression of miR-320a-3p restored the epithelial phenotype of A549 cells. suggesting a suppressive role for miR-320a-3p in PF progression.

STAT3, a member of the STAT family of protein, is a cytoplasmic transcription factor that can be activated by multiple cytokines. The activation of STAT3 regulates a variety of biological functions, including apoptosis, migration, proliferation and differentiation $(19,20)$. The role of STAT3 in fibrosis remains to be elucidated. According to different experimental subjects, related studies have produced conflicting results (21-23). Regarding PF, the majority of studies reveal elevated levels of p-STAT3 in patients with PF (24-26). Evidence supports a role for STAT3 activation 
A

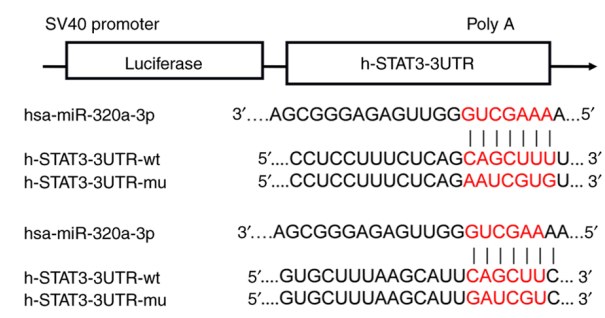

B

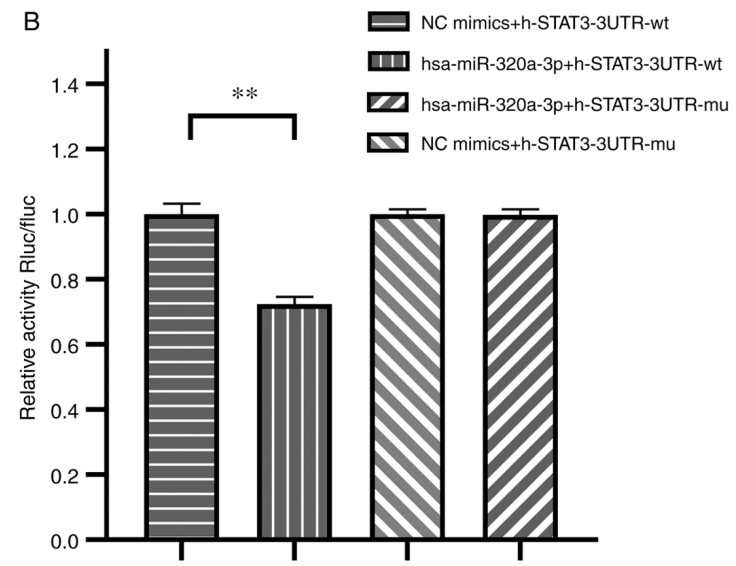

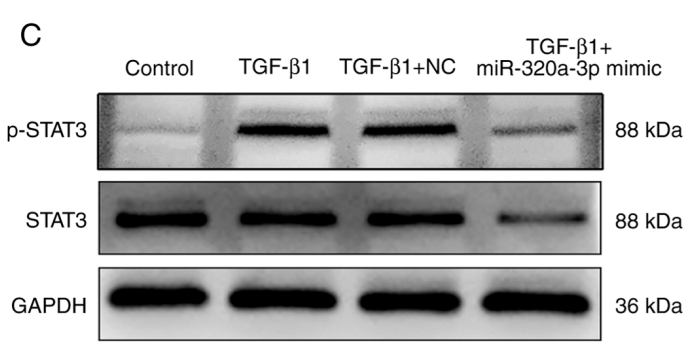
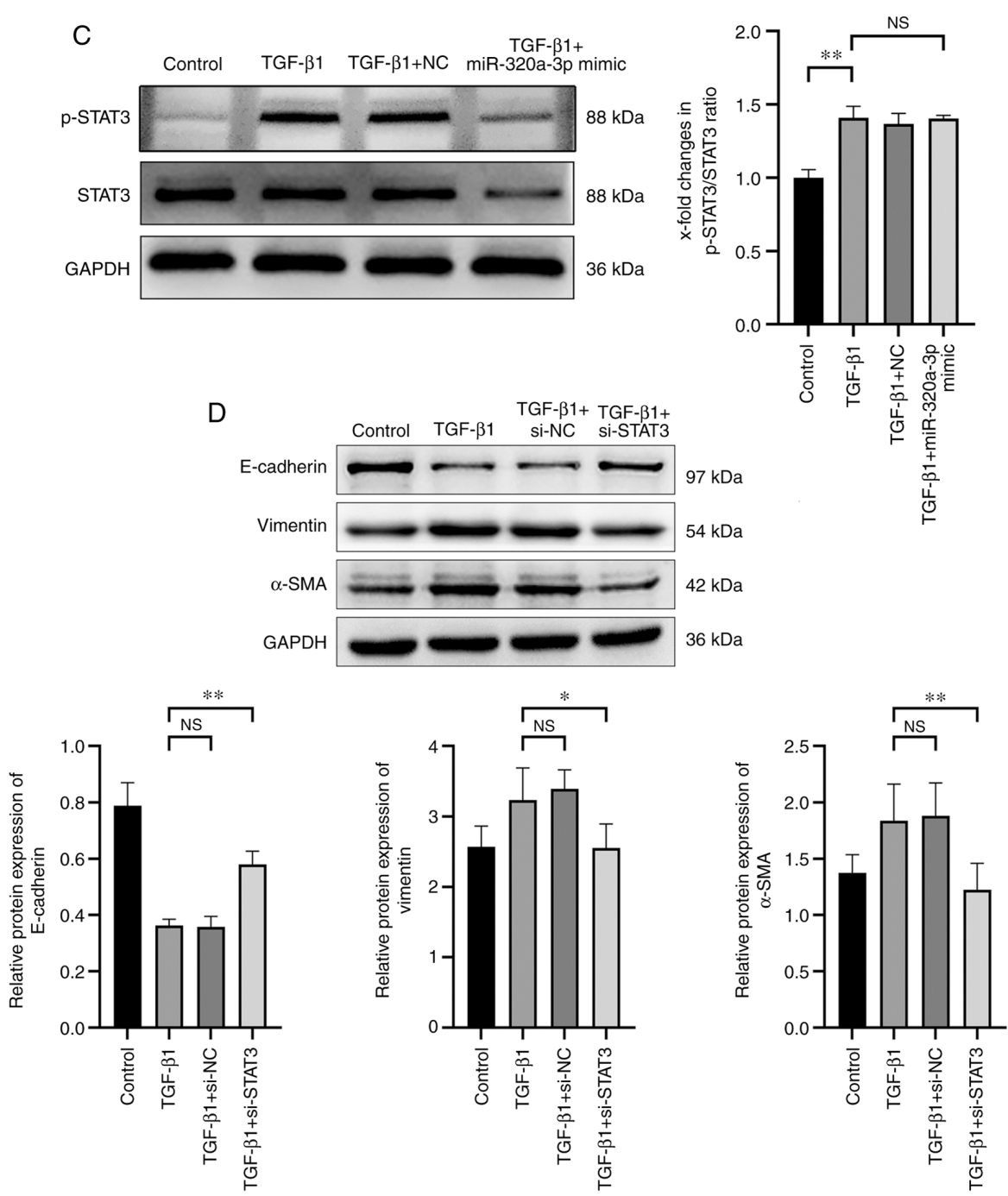

Figure 3. Continued

in PF. Zehender et al (25) reports that STAT3 contributes to induces the transformation of fibroblasts into myofibroblasts, leading to abnormal accumulation of extracellular matrix (ECM). Pedroza et al (20) demonstrate that the STAT3 signaling pathway is aberrantly activated in lung biopsies from patients with IPF and in lung tissue from PF animal models. Considering the importance of STAT3 in the development of PF, STAT3 would be a potential target for intervention of the EMT process in PF. The present study used bioinformatics tools and dual-luciferase assay to show that miR-320a-3p directly regulated STAT3. The expression of p-STAT-3 was shown to be elevated in TGF- $\beta 1$-treated A549 cells and subsequent experiments confirmed that overexpression of miR-320a-3p can significantly inhibit such high expression of STAT3 and p-STAT3 levels. The present study found that the ratio of p-STAT3 and STAT3 did not decrease in the TGF- $\beta 1+$ miR-320a-3p mimic group compared with the TGF- $\beta 1$ treatment group. This may be 
E
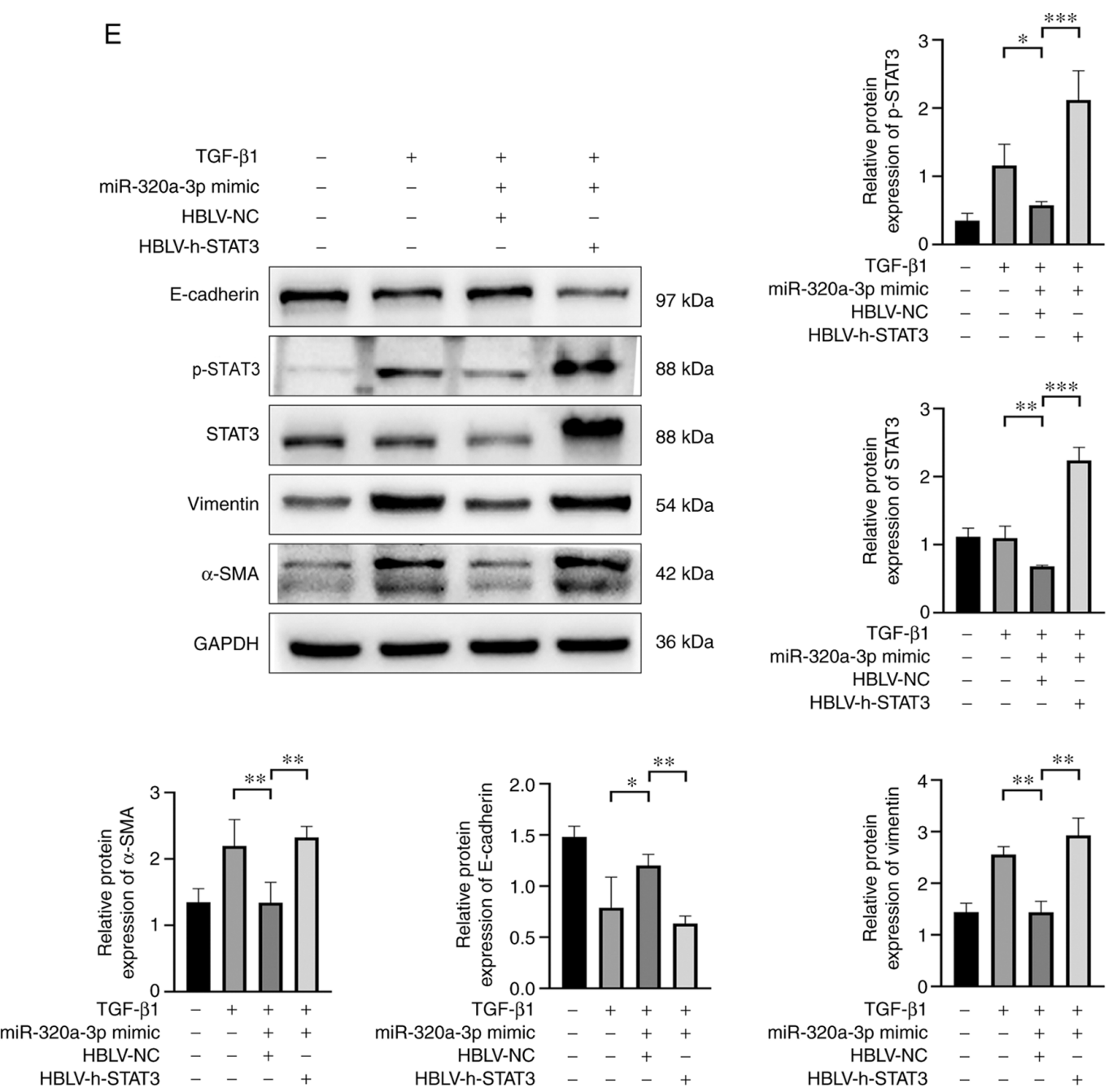

F

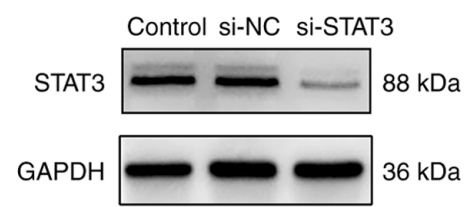

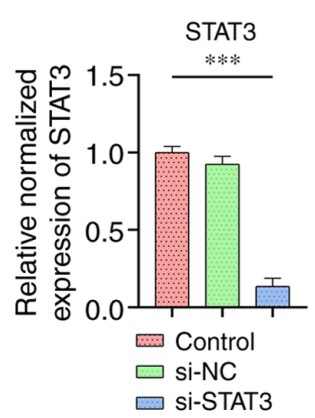

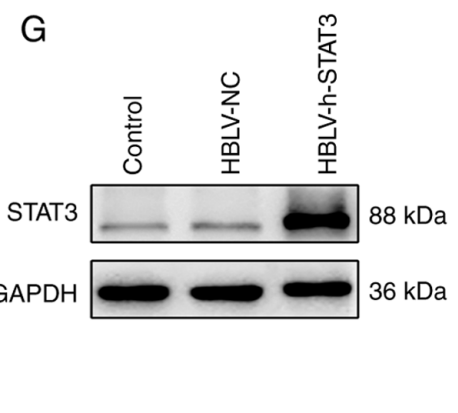

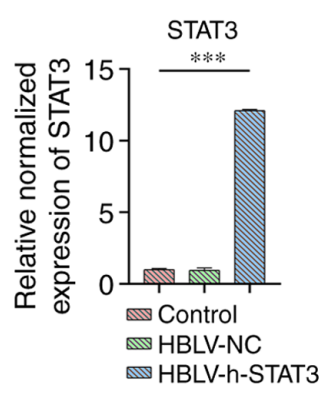

Figure 3. STAT3 is a target gene of miR-320a-3p and effects of STAT3 on EMT in A549 cells induced by TGF- $\beta 1$. Dual-luciferase reporter assay. (A) The STAT3 3'-UTR region containing the wild-type (wt) or mutant (mu) binding site for miR-320a-3p. (B) Relative Rluc/fluc activity of cells co-transfected with either wt pSI-Check2-STAT3-3'-UTR or pSI-Check2-STAT3-mut-3'-UTR and miR-320a-3p mimic or corresponding NC. (C) A549 cells were treated with or without TGF- $\beta 1(10 \mathrm{ng} / \mathrm{ml})$ for $48 \mathrm{~h}$ after transfection with miR-320a-3p mimic or NC. The expression of p-STAT3, STAT3 were determined by western blot analysis and their ratio were analyzed. (D) A549 cells were treated with or without TGF- $\beta 1(10 \mathrm{ng} / \mathrm{ml})$ for $48 \mathrm{~h}$ after transfection with STAT3 siRNA or NC siRNA. To confirm the effects of STAT3 on the EMT in A549 cells, the expression of E-cadherin, vimentin and $\alpha$-SMA were determined by western blot analysis. (E) A549 cells were treated with or without TGF- $\beta 1(10 \mathrm{ng} / \mathrm{ml})$ for $48 \mathrm{~h}$ after co-transfection with miR-320a-3p mimic and HBLV-h-STAT3 or HBLV-NC. The expression of E-cadherin, vimentin, $\alpha$-SMA, p-STAT3 and STAT3 were determined by western blot analysis. The transfection efficiency of (F) si-STAT3 and (G) HBLV-h-STAT3 were determined by western blot analysis. Error bars represent the standard deviation of three experiments. "P<0.05, ${ }^{* *} \mathrm{P}<0.01,{ }^{* * *} \mathrm{P}<0.001$. miR, microRNA; EMT, epithelial-mesenchymal transition; UTR; wt, wild-type; mu, mutant; Rluc/fluc, Renilla luciferase/firefly luciferase; NC, negative controls; $p$-, phosphorylated; si, short interfering; $\alpha$-SMA, $\alpha$-smooth muscle actin; NS, no significant difference.

because the reduction of p-STAT3 follows the total STAT3 and miR-320a-3p does not affect the phosphorylation process of STAT3. Furthermore, western blot analysis demonstrated that knocking down STAT3 could suppress the expression of multiple EMT markers in TGF- $\beta 1$-treated A549 cells, whereas overexpression of STAT3 could aggravate the above-mentioned EMT performance. These results indicated that miR-320a-3p reduced the expression of p-STAT3 by binding to STAT3, thereby inhibiting the EMT process in PF. It also illustrated the role served by STAT3 in the regulation 

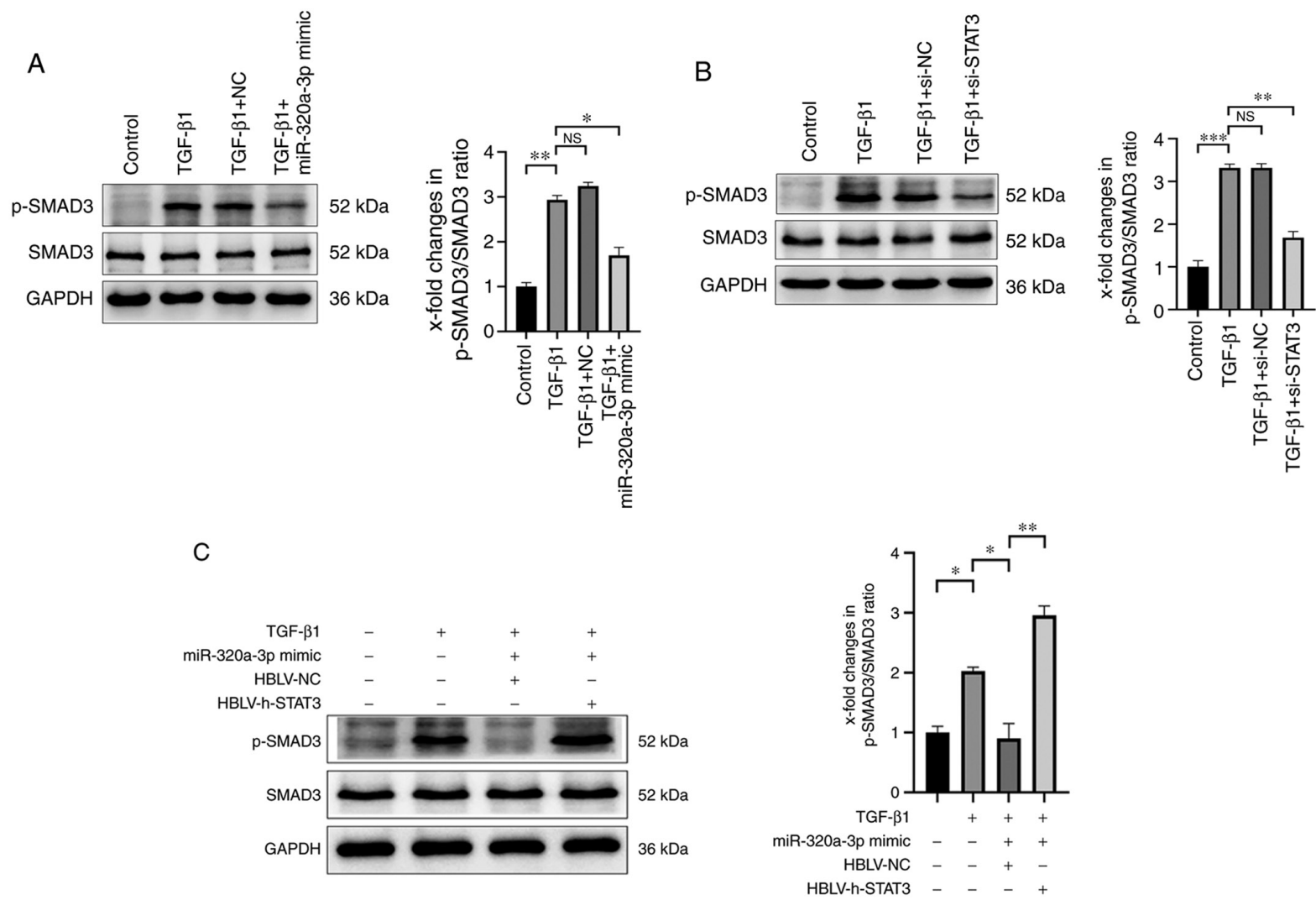

Figure 4. miR-320a-3p and STAT3 regulate the p-SMAD3 in A549 cells. (A) A549 cells were treated with or without TGF- $\beta 1$ (10 ng/ml) for $1 \mathrm{~h}$ after transfection with miR-320a-3p mimic or NC. (B) A549 cells were treated with or without TGF- $\beta 1(10 \mathrm{ng} / \mathrm{ml})$ for $1 \mathrm{~h}$ after transfection with STAT3 siRNA or NC siRNA. (C) A549 cells were treated with or without TGF- $\beta 1(10 \mathrm{ng} / \mathrm{ml})$ for $1 \mathrm{~h}$ after co-transfection with miR-320a-3p mimic and HBLV-h-STAT3 or HBLV-NC. Levels of SMAD3 and p-SMAD3 were determined by western blot analysis. Error bars represent the standard deviation of three experiments. ${ }^{*} \mathrm{P}<0.05,{ }^{* *} \mathrm{P}<0.01,{ }^{* * *} \mathrm{P}<0.001$. miR, microRNA; -, phosphorylated; NC, negative controls; si, short interfering; NS, no significant difference.

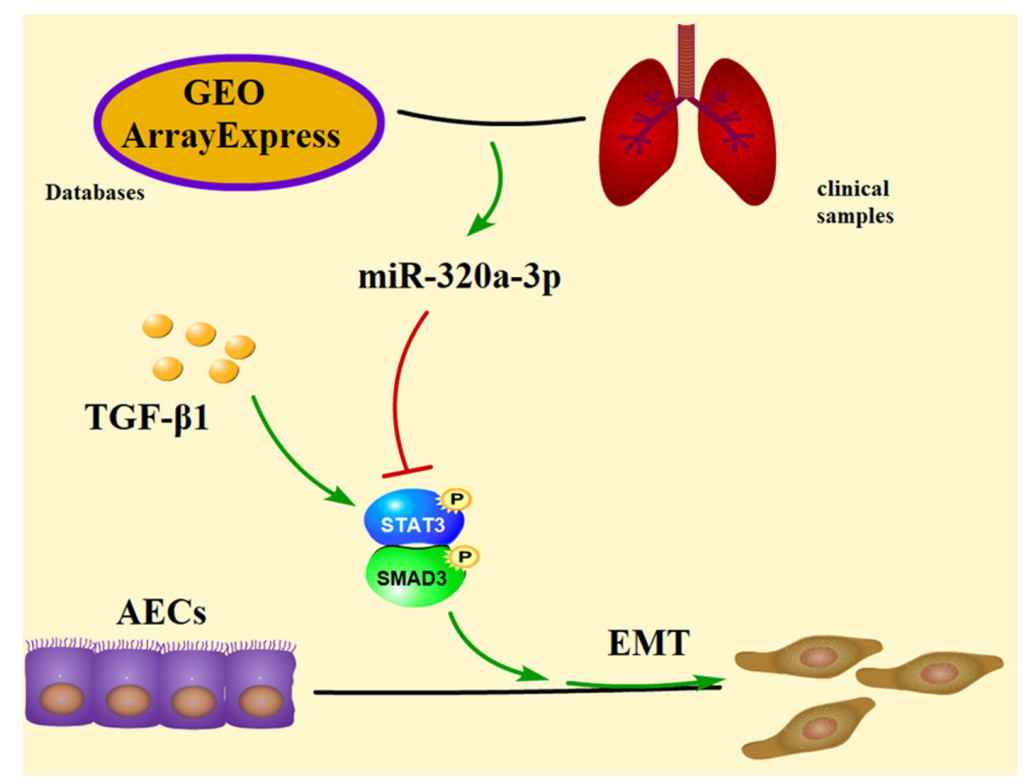

Figure 5. Study design and miR-320a-3p protected against EMT in PF through STAT3/SMAD3 signaling pathways. miR, microRNA; EMT, epithelial-mesenchymal transition; PF, pulmonary fibrosis; GEO, Gene Expression Omnibus; AECs, alveolar epithelial cells.

of the expression of EMT-related genes in A549 cells stimulated by TGF- $\beta 1$.

TGF- $\beta$ is a multifunctional cytokine key mediator in the initiation of tissue repair, especially in the kidney, liver and lung, belonging to the transforming growth factor superfamily that includes three isoforms (TGF- $\beta 1-3$ ) and other cytokines (27). Among the TGF- $\beta$ isoforms, TGF- $\beta 1$ is the one most associated with PF. Elevated levels of TGF- $\beta 1$ are reported in the 
bleomycin (BLM)-induced PF rat model as well as in patients with IPF $(28,29)$. Differentiation of fibroblasts and synthesis of ECM proteins caused by overproduction of TGF- $\beta 1$ contribute to the pathogenesis of PF (30). The signal transduction of the TGF- $\beta$ family is mediated by TGF $\beta$ RII, which recruits TGF $\beta$ RI and activates various signaling pathways, including pathways mediated by Smad signaling proteins (31). Smads act as intracellular effectors in response to TGF- $\beta$ and once inside the nucleus, Smad complexes bind regulatory elements and induce the transcription of key genes associated with EMT (31). In addition, activation by Smads promotes fibroblast proliferation, differentiation and ECM remodeling (32). Crosstalk between the Smad and STAT3 pathways has been proposed. A cooperative role of STAT3 and TGF- $\beta 1 /$ SMAD3 has been reported in hepatic fibrosis (33), while in $\mathrm{HaCaT}$ and HepG2 cells a physical direct interaction between STAT3 and SMAD3 attenuating the TGF- $\beta 1$-induced response has been suggested (34). These results varied depending on the cell type and disease model studied and, although conflicting, indicate crosstalk between TGF- $\beta 1$ and STAT3 signaling pathways. The present study observed that miR-320a-3p mimic and STAT3 siRNA could reduce the phosphorylation of SMAD3 induced by TGF- $\beta 1$ in A549 cells. By contrast, overexpression of STAT3 could dramatically increase the levels of p-SMAD3, implying that STAT3 might induce SMAD3 activation in the EMT process of type II alveolar epithelial cells.

The present study demonstrated that the expression levels of miR-320a-3p were decreased in PF tissue samples compared with normal tissue samples. Via stimulation by TGF- $\beta 1$, A549 cells exhibited the EMT phenotype and the levels of miR-320a-3p in A549 cells decreased in a time- and concentration-dependent manner. TGF- $\beta 1$ can induce EMT in A549 cells, as manifested by a decrease in E-cadherin and an increase in vimentin and $\alpha$-SMA. STAT3 was activated in TGF- $\beta 1$-treated A549 cells and the phosphorylation of STAT3 served an important role in the development of the EMT process. The present study also investigated the underlying molecular mechanisms by which miR-320a-3p attenuated EMT in PF. The phosphorylation of STAT3 and SMAD3 proteins was generally high in A549 cells treated with TGF- $\beta 1$ and their co-expression was positively associated with TGF- $\beta 1$. Higher p-STAT3 levels were related to more prominent EMT process. Overexpression of miR-320a-3p could attenuate the development of the EMT process in PF by binding STAT3. The mechanism may be partly mediated through crosstalk between the SMAD3 and STAT3 signaling. These results not only have important implications for our understanding of STAT3 signaling in the development of PF but also for the potential role of miR-320a-3p as a therapeutic target in PF. Overall, miR-320a-3p had an effect that reduced the expression levels of phosphorylation of STAT3, decreases p-SMAD3 protein levels and inhibited the TGF- $\beta 1$-induced EMT process in type II AECs. The design and main results of the present study are shown in a schematic diagram (Fig. 5).

Finally, the following limitations should be considered in the present study: i) Due to various factors, the in vivo experiment was not completed. This part of the content served a very important role in supporting the whole theory. Therefore, in the future, we will further explore the effects of miR-320a-3p in PF animal models; ii) the present study was limited to the effect of miR-320a-3p on EMT in PF and its corresponding effect in the STAT3/SMAD3 signaling pathway. The present study failed to cover other related factors, such as long non-coding RNA, other genetic data or other signaling pathways. This will also be the focus of future research.

\section{Acknowledgements}

Not applicable.

\section{Funding}

This study was supported by National Major Science and Technology Projects of China (grant no. 2018ZX10302302003) and National Natural Science Foundation of China (grant nos. 81601856 and 81570010).

\section{Availability of data and materials}

The datasets used and/or analyzed during the current study are available from the corresponding author on reasonable request. The datasets generated and/or analyzed during the current study are available in the Gene Expression Omnibus (https://www.ncbi.nlm.nih.gov/gds) and ArrayExpress (https://www.ebi.ac.uk/arrayexpress/) repository.

\section{Authors' contributions}

XW, GH, YL and SG conceived and designed the project. XW and JW acquired the data and wrote the paper. XW, JW and GH analyzed interpreted the data. XW, JW and GH were responsible for confirming the authenticity of the data in the present study. All authors read and approved the final manuscript.

\section{Ethics approval and consent to participate}

The collection and analysis of all samples were approved by the Ethics Research Institute of the First Affiliated Hospital of Chongqing Medical University (approval no. 2020-147-2) and written informed consent was obtained from all the participants.

\section{Patient consent for publication}

Not applicable.

\section{Competing interests}

The authors declare that they have no competing interests.

\section{References}

1. Kim MH, Jung SY, Song KH, Park JI, Ahn J, Kim EH, Park JK, Hwang SG, Woo HJ and Song JY: A new FGFR inhibitor disrupts the TGF- $\beta 1$-induced fibrotic process. J Cell Mol Med 24: 830-840, 2020

2. Barratt SL, Creamer A, Hayton C and Chaudhuri N: Idiopathic pulmonary fibrosis (IPF): An overview. J Clin Med 7: 201, 2018.

3. Selman M, King TE and Pardo A: Idiopathic pulmonary fibrosis: Prevailing and evolving hypotheses about its pathogenesis and implications for therapy. Ann Internal Med 134: 136-151, 2001. 
4. Kim KK, Kugler MC, Wolters PJ, Robillard L, Galvez MG, Brumwell AN, Sheppard D and Chapman HA: Alveolar epithelial cell mesenchymal transition develops in vivo during pulmonary fibrosis and is regulated by the extracellular matrix. Proc Natl Acad Sci USA 103: 13180-13185, 2006.

5. Willis BC, Liebler JM, Luby-Phelps K, Nicholson AG, Crandall ED, du Bois RM and Borok Z: Induction of epithelial-mesenchymal transition in alveolar epithelial cells by transforming growth factor-beta1: Potential role in idiopathic pulmonary fibrosis. Am J Pathol 166: 1321-1332, 2005.

6. Pardali E, Sanchez-Duffhues G, Gomez-Puerto MC and Ten Dijke P: TGF- $\beta$-induced endothelial-mesenchymal transition in fibrotic diseases. Int J Mol Sci 18: 2157, 2017.

7. Aquino-Jarquin G: Emerging role of CRISPR/Cas9 technology for MicroRNAs editing in cancer research. Cancer Res 77 6812-6817, 2017

8. Gai YP, Zhao HN, Zhao YN, Zhu BS, Yuan SS, Li S, Guo FY and Ji XL: MiRNA-seq-based profiles of miRNAs in mulberry phloem sap provide insight into the pathogenic mechanisms of mulberry yellow dwarf disease. Sci Rep 8: 812, 2018.

9. Mittal V: Epithelial mesenchymal transition in tumor metastasis. Ann Rev Pathol 13: 395-412, 2018.

10. Aljagthmi AA, Hill NT, Cooke M, Kazanietz MG, Abba MC, Long $\mathrm{W}$ and Kadakia MP: $\Delta \mathrm{Np} 63 \alpha$ suppresses cells invasion by downregulating PKC $\gamma /$ Racl signaling through miR-320a. Cel Death Dis 10: 680, 2019.

11. Zhang HH, Li R, Li YJ, Yu XX, Sun QN, Li AY and Kong Y: eIF4E-related miR-320a and miR-340-5p inhibit endometrial carcinoma cell metastatic capability by preventing TGF- $\beta 1$-induced epithelial-mesenchymal transition. Oncol Rep 43: 447-460, 2020.

12. Livak KJ and Schmittgen TD: Analysis of relative gene expression data using real-time quantitative PCR and the 2(-Delta Delta C(T)) method. Methods 25: 402-408, 2001

13. Waters DW, Blokland KEC, Pathinayake PS, Burgess JK, Mutsaers SE, Prele CM, Schuliga M, Grainge CL and Knight DA: Fibroblast senescence in the pathology of idiopathic pulmonary fibrosis. Am J Physiol Lung Cell Mol Physiol 315: L162-1172, 2018.

14. Huang C, Xiao X, Yang Y, Mishra A, Liang Y, Zeng X, Yang X, Xu D, Blackburn MR, Henke CA and Liu L: MicroRNA-101 attenuates pulmonary fibrosis by inhibiting fibroblast proliferation and activation. J Biol Chem 292: 16420-16439, 2017.

15. Wang Y, Liang Y, Luo J, Nie J, Yin H, Chen Q, Dong J, Zhu J, Xia J and Shuai W: XIST/miR-139 axis regulates bleomycin (BLM)-induced extracellular matrix (ECM) and pulmonary fibrosis through $\beta$-catenin. Oncotarget 8: 65359-65369, 2017.

16. Yang ZC, Qu ZH, Yi MJ, Shan YC, Ran N, Xu L and Liu XJ: MiR-448-5p inhibits TGF- $\beta 1$-induced epithelial-mesenchymal transition and pulmonary fibrosis by targeting Six1 in asthma. J Cell Physiol 234: 8804-8814, 2019.

17. Foster KA, Oster CG, Mayer MM, Avery ML and Audus KL: Characterization of the A549 cell line as a type II pulmonary epithelial cell model for drug metabolism. Exp Cell Res 243: 359-366, 1998

18. Lieber M, Smith B, Szakal A, Nelson-Rees W and Todaro G: A continuous tumor-cell line from a human lung carcinoma with properties of type II alveolar epithelial cells. Int J Cancer 17: 62-70, 1976.

19. Levy DE and Darnell JE Jr: Stats: Transcriptional control and biological impact. Nat Rev Mol Cell Biol 3: 651-662, 2002.
20. Pedroza M, Le TT, Lewis K, Karmouty-Quintana H, To S, George AT, Blackburn MR, Tweardy DJ and Agarwal SK: STAT-3 contributes to pulmonary fibrosis through epithelial injury and fibroblast-myofibroblast differentiation. FASEB J 30: 129-140, 2016.

21. Dai B, Cui M, Zhu M, Su WL, Qiu MC and Zhang H: STAT1/3 and ERK1/2 synergistically regulate cardiac fibrosis induced by high glucose. Cell Physiol Biochem 32: 960-971, 2013.

22. Ogata H, Chinen T, Yoshida T, Kinjyo I, Takaesu G, Shiraishi H, Iida M, Kobayashi T and Yoshimura A: Loss of SOCS3 in the liver promotes fibrosis by enhancing STAT3-mediated TGF-betal production. Oncogene 25: 2520-2530, 2006.

23. Shigekawa M, Takehara T, Kodama T, Hikita H, Shimizu S, Li W, Miyagi T, Hosui A, Tatsumi T, Ishida H, et al: Involvement of STAT3-regulated hepatic soluble factors in attenuation of stellate cell activity and liver fibrogenesis in mice. Biochem Biophys Res Commun 406: 614-620, 2011.

24. Le TT, Karmouty-Quintana H, Melicoff E, Le TT, Weng T, Chen NY, Pedroza M, Zhou Y, Davies J, Philip K, et al: Blockade of IL-6 Trans signaling attenuates pulmonary fibrosis. J Immunol 193: 3755-3768, 2014.

25. Zehender A, Huang J, Györfi AH, Matei AE, Trinh-Minh T, Xu X, Li YN, Chen CW, Lin J, Dees C, et al: The tyrosine phosphatase SHP2 controls TGF $\beta$-induced STAT3 signaling to regulate fibroblast activation and fibrosis. Nat Commun 9: 3259, 2018.

26. Xu Q, Liu Y, Pan H, Xu T, Li Y, Yuan J, Li P, Yao W, Yan W and Ni C: Aberrant expression of miR-125a-3p promotes fibroblast activation via Fyn/STAT3 pathway during silica-induced pulmonary fibrosis. Toxicology 414: 57-67, 2019.

27. Morikawa M, Derynck R and Miyazono K: TGF- $\beta$ and the TGF- $\beta$ family: Context-dependent roles in cell and tissue physiology. Cold Spring Harbor Perspect Biol 8: a021873, 2016.

28. Ask K, Bonniaud P, Maass K, Eickelberg O, Margetts PJ, Warburton D, Groffen J, Gauldie J and Kolb M: Progressive pulmonary fibrosis is mediated by TGF-beta isoform 1 but not TGF-beta3. Int J Biochem Cell Biol 40: 484-495, 2008.

29. Border WA and Noble NA: Transforming growth factor beta in tissue fibrosis. N Engl J Med 331: 1286-1292, 1994.

30. Wynn TA and Ramalingam TR: Mechanisms of fibrosis: Therapeutic translation for fibrotic disease. Nat Med 18: 1028-1040, 2012.

31. Feng XH and Derynck R: Specificity and versatility in tgf-beta signaling through Smads. Annu Rev Cell Dev Biol 21: 659-693, 2005.

32. Walton KL, Johnson KE and Harrison CA: Targeting TGF- $\beta$ mediated SMAD signaling for the prevention of fibrosis. Front Pharmacol 8: 461, 2017.

33. Tang LY, Heller M, Meng Z, Yu LR, Tang Y, Zhou M and Zhang YE: Transforming Growth Factor- $\beta$ (TGF- $\beta$ ) directly activates the JAK1-STAT3 axis to induce hepatic fibrosis in coordination with the SMAD pathway. J Biol Chem 292: 4302-4312, 2017.

34. Wang G, Yu Y, Sun C, Liu T, Liang T, Zhan L, Lin X and Feng XH: STAT3 selectively interacts with $\mathrm{Smad} 3$ to antagonize TGF- $\beta$ signalling. Oncogene 35: 4388-4398, 2016.

This work is licensed under a Creative Commons Attribution-NonCommercial-NoDerivatives 4.0 International (CC BY-NC-ND 4.0) License. 